\title{
Biology of seed development and germination physiology
}

\begin{abstract}
The evolution of the seed represents a remarkable transition for photosynthetic organisms. It is the most complex and successful method of sexual reproduction in vascular plants. Seed contain the genetic wisdom of the past and the potential for its perpetuation in the future. Seeds remain in a state of dormancy induced by desiccation and the hormone abscisic acid until conditions for growth become favorable. Seed evolution eliminates requirement for water during sexual reproduction and allows fertilization event to occur over long distances. The germination of seeds in a particular situation and season is determined by the interaction between the dormancy releasing factors, which influence on the termination of dormancy or initiation of germination and seedling growth in many plant species like phyto-hormones, light, temperature, water, nutrients, moisture or mechanical cues. Seeds of different plants need different pretreatment to get vigor seedling and even for production. Therefore, real attention should be given for the plant propagation, particularly for indigenous tree species and seedling multiplication should be considered as our culture to make suitable environment.
\end{abstract}

Keywords: ovule, seed, dormancy, physiology, germination
Volume 8 Issue 4 - 2018

Tura Bareke

Oromia Agricultural Research Institute, Holeta Bee Research Center, Ethiopia

Correspondence: Tura Bareke, Oromia Agricultural Research Institute, Holeta Bee Research Center, Ethiopia, Email trbareke@gmail.com

Received: Septembre 12, 2017| Published: August 08, 2018

\section{Introduction}

All land plants are believed to have had their origin in a unicellular green algal ancestor. The ancestors of early plants were highly dependent on water, not only to maintain their moisture contents but also for structural support. In a terrestrial environment, the surrounding media is air rather than water. Air does not provide any support for upright growth. Because desiccation, or drying out, is a constant danger for organisms exposed to air. However, with the evolution of key morphological innovations, plant-dominated ecosystem has gradually increased leading to major biome formation (Boundless, 2014). The more sophisticated and differentiated multi cellular anatomy, the invention of new reproductive structures and strategies were fundamental for the success of terrestrial colonization by plants. ${ }^{1}$ There are several reproductive adaptations in plants. The first is the ability to alternate life cycle stages between a diploid (sporophyte) and multi-cellular haploid stage (gametophyte). Related to this adaptation is the evolutionary trend to increase the size and independence of the sporophyte. Evolution of pollen is also an adaptation that allows reproduction to occur over great distances and in the absence of free water. Seeds allow for a dormancy stage and provide food for the developing embryo. Flowers promote efficient pollination, and fruits aid in seed protection and dispersal. ${ }^{2}$ The seed habit is the most complex and successful method of sexual reproduction in vascular plants. The seed plants comprise two major groups: the Acrogymnospermae (also referred to as gymnosperms; c. 800 living species) and the Angiosperm (also referred to as angiosperms; c. 250000 living species). ${ }^{3}$ These groups are by far the most diverse lineages within the vascular plants. Gymnosperms have no flowers or fruits, and have unenclosed or "naked" seeds on the surface of scales or leaves. Gymnosperm seeds are often configured as cones, while angiosperms, also called flowering plants, have seeds that are enclosed within an ovary (usually a fruit). The characteristics that differentiate angiosperms from gymnosperms include flowers, fruits, and endosperm in the seeds. ${ }^{4}$ Seeds are the connection between the past and the future. They contain the genetic wisdom of the past and the potential for its perpetuation in the future. The natural packaging of genetic information in a seed is remarkable in itself as a package to protect the genotype for long periods of time when properly stored in germplasm collections. Therefore, this review gives an overview of the seed evolution, Biology of seed development and germination physiology of seed.

\section{Adaptive mechanism of plants on land}

The major challenge for early plants first migrating onto land was the lack of water. To overcome such problem, plants have been developed the new structures that help them to colonizing the new and dry environments. ${ }^{2}$ (Table 1)

\section{Seed evolution}

The seed plants are a monophyletic lineage within the lignophytes. The major evolutionary novelty that unites this group is the seed. A seed is defined as an embryo, which is an immature diploid sporophyte developing from the zygote, surrounded by nutritive tissue and enveloped by a seed coat. The embryo generally consists of an immature root called the radicle, a shoot apical meristem called the epicotyls, and one or more young seed leaves, the cotyledons; the transition region between root and stem is called the hypocotyls. An immature seed, prior to fertilization, is known as an ovule. ${ }^{5}$ (Figure 1) Evidence from the fossil plant record indicates that plants were producing sporangia yielding two kinds of spores from the early Devonian ( $\sim 140$ million years ago). These include megaspores and microspores. ${ }^{6}$ The transition from plants that were homo sporous (one spore size) to heterosporous (two spores' sizes) is considered one of the most important evolutionary trends in the development of seedbearing plants. It is postulated that the larger spores of heterosporous 
plants were the precursor of ovules, and the small spores, the precursor to pollen. Retention of the megaspore in the megaspore in the mega sporangium was the first in the direction towards evolution of the ovule. The evolution of the seed represents a remarkable lifehistory transition for photosynthetic organisms. The evolution of the seed involved several steps. The exact sequence of these is not certain, and two or more steps in seed evolution may have occurred concomitantly. ${ }^{5}$

The probable steps in seed evolution are as follows:

A. Heterospory: Heterospory is the formation of two types of haploid spores within two types of sporangia: large, fewer numbered megaspores, which develop via meiosis in the mega sporangium, and small, more numerous microspores, the products of meiosis in the microsporangium. The ancestral condition, in which a single spore type forms, is called homospory. Each megaspore develops into a female gametophyte that bears only archegonia; a microspore develops into a male gametophyte, bearing only antheridia. Although Heterospory was prerequisite to seed evolution, there are fossil plants that were heterosporous but had not evolved seeds, among these being species of $\mathrm{Ar}$ cheopteris. Note that heterospory has evolved independently in other, non-seed plants, e.g., in the extant lycophytes Selaginella and Isoetes and in the water ferns.

B. Endospory: Endospory is the complete development of the female gametophyte within the original spore wall. The ancestral condition, in which the spore germinates and grows as an external gametophyte, is called exospory.

C. Reduction of megaspore number to one: Reduction of megaspore number occurred in two ways. First, there evolved a reduction in the number of cells within the mega sporangium that undergo meiosis (each termed a megasporocyteor megaspore mother cell) was reduced to one. After meiosis, the single diploid megasporocyte gives rise to four haploid megaspores. Second, of the four haploid megaspores produced by meiosis, three consistently abort, leaving only one functional megaspore.
This single megaspore also undergoes a great increase in size, correlated with the increased availability of space and resources in the mega sporangium.

D. Retention of the megaspore: This was accompanied by a reduction in thickness of the megaspore wall.

E. Evolution of the integument: Most likely, the final event in seed evolution was the envelopment of the mega sporangium by tissue, called the integument. The integument grows from the base of the mega sporangium (which is often called a nucellus when surrounded by an integument) and surrounds it, except at the distal end. ${ }^{5}$

\section{Significance of seed evolution}

Unlike bryophyte and fern spores (which are haploid cells dependent on moisture for rapid development of gametophytes), seeds contain a diploid embryo that will germinate into a sporophyte. It has storage tissue to sustain growth and a protective coat give seeds their superior evolutionary advantage. Several layers of hardened tissue prevent desiccation, freeing reproduction from the need for a constant supply of water. Furthermore, seeds remain in a state of dormancy induced by desiccation and the hormone abscisic acid until conditions for growth become favorable. Whether blown by the wind, floating on water, or carried away by animals, seeds are scattered in an expanding geographic range, thus avoiding competition with the parent plant. ${ }^{2}$ From an ecological perspective, seeds are at the intersection of a species with its environment. The fundamental reason for the existence of seeds is to assure the survival of plant species. Beyond this important biological function, they represent the basis to high agricultural productivity and play an important role as a direct and indirect source of food for humans and animals, materials for industry and other essential products for the maintenance and improvement of the quality of human life. In this way, as plant breeding becomes more diversified and provides surprising results, there are increases in demand for seeds with enhanced attributes and efficient performance in field.

Table I Four major groups of plant with their own key biological events or new biological structure summarized from Willis and McElwain, (2002).

Bryophyte (liverworts, hornworts, and mosses)

Stem, Microphyll and spore

Tracheids,

Vascular tissue,

Megaphyll, Root,

heterospory and

Dominant sporophyte
Stem-provide mechanical support

Microphyll-photosynthesis

Spore- is a structure used to disperse the

plant's offspring to new locations and survive harsh environmental conditions like dryness, no O2, UV light.

Tracheids- are elongated cells in the xylem of vascular plants that serve in the transport of water and mineral salts

Vascular tissue- used for mechanical support

Megaphyll- for photosynthesis

Roots -are organs that anchor vascular

plants and enable them to absorb water and nutrients from the soil and allow the shoot system to grow taller. Roots may have evolved from the subterranean portions of stems in ancient vascular plants.

Heterospory: produce two kinds of spore, - Megaspore - produce female gametophyte and it's precursor of ovule

- Microspore-- produce male gametophyte and precursor of pollen grain

Dominant sporophyte 
Table Continued

\begin{tabular}{|c|c|c|}
\hline Groups of plants & Key biological events & Their uses \\
\hline Gymnosperm & $\begin{array}{l}\text { Pollen grain and } \\
\text { seed }\end{array}$ & $\begin{array}{l}\text { Pollen grain- seen fossil evidence } \sim 364 \text { Mya, } \\
\text { represent adaptation of the male part in plant } \\
\text { life cycle. Extant heterosporous plants } \rightarrow \\
\text { microspores liberated flagellate gametes from } \\
\text { the end of spore } \rightarrow \text { pollen grains produced } \\
\text { tubes that direct gametes to ovules } \\
\text { 2. Seed: contains a well-developed multi } \\
\text { cellular young plant with embryonic root, } \\
\text { stem, and leaves already formed, whereas } \\
\text { a plant spore is a single cell. The seed is } \\
\text { protected by a multi cellular coat. Seeds (and } \\
\text { spores) can survive for extended periods } \\
\text { of time at reduced rates of metabolism and } \\
\text { then germinate when conditions become } \\
\text { favorable. }\end{array}$ \\
\hline Angiosperm & $\begin{array}{l}\text { Double fertilization, } \\
\text { Flower, } \\
\text { fruit, } \\
\text { ovule and } \\
\text { vessels }\end{array}$ & $\begin{array}{l}\text { 1. Double fertilization- this process is unique } \\
\text { to angiosperm, a single pollen grain has two } \\
\text { sperm and a single ovary also has an egg and } \\
\text { a central nucleate cell. Double fertilization } \\
\text { occurs when one of these sperm combines } \\
\text { with the egg to become the embryo and the } \\
\text { other sperm combines with central nuclei and } \\
\text { become endosperm of the growing seeds. } \\
\text { 2. Flower- the most remarkable feature } \\
\text { distinguishing the angiosperm from other } \\
\text { seed plants. Used flowering plants dominate } \\
\text { terrestrial ecosystem } \\
\text { 3.Ovule- evidence from the of plant fossil } \\
\text { record indicate that by the end of Devonian } \\
\text { ovule developed from megaspore, involving } \\
\text { the abortion of three out of the four spore } \\
\text { in sporangium to form a single functional } \\
\text { megaspore. Retention of megaspore in the } \\
\text { mega sporangium and development of a seed } \\
\text { coat were very important in the evolution of } \\
\text { the ovule. } \\
\text { 4. Fruit- used to enclose the seed and increase } \\
\text { the domination of angiosperm on terrestrial } \\
\text { ecosystem with evolutionary adaptation to } \\
\text { dispersal mechanism } \\
5 \text {. Vessels-is one of the cell types found in } \\
\text { xylem, the water conducting tissue of plants. } \\
\text { They are the main feature distinguishing } \\
\text { the "hardwood" of angiosperms from the } \\
\text { "softwood" of conifers }\end{array}$ \\
\hline
\end{tabular}

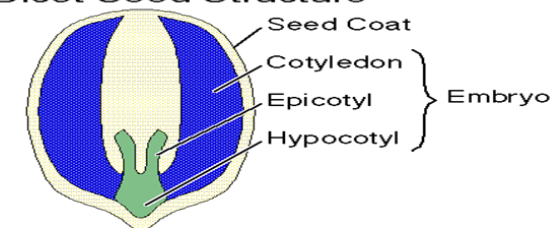

Monocot Seed Structure

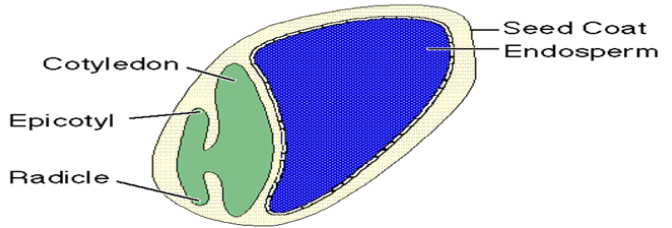

Figure I Seed Germinated structures for monocot and dicot plants. 


\section{Seed development}

The seed development process, from ovule fertilization to physiological maturity, can be divided into four phases according to http://agritech.tnau.ac.in/seed/seedconcepts.html. Phases I and II comprise cell division and expansion. Reserve accumulation occurs in Phase III as seed dry mass increases. At the end of this phase, seed moisture loss is intensified (Phase IV). http://agritech.tnau.ac.in/seed/ seedconcepts.htmlreported that, after fertilization, there is a period of seed structure formation as a result of cell division, expansion and differentiation (histodifferentiation) in which seed structure primordia are formed and future embryo parts can be visualized. During this phase, there is a significant increase in seed size forming the embryonic cells that receive assimilates from the parent plant. During this period, seed moisture content remains constant and high. The significant decrease in seed moisture content occurs at the end of maturation when changes in cell membrane structure organization occurs as well as increases in enzyme synthesis in preparation for successful germination. Recalcitrant seeds usually do not show this transition period between maturation and germination.

\section{Pollination and fertilization}

Pollination is the transfer of pollen from the anther to the stigma after it germinates. The pollen grain has two cells, the tube nuclei and the generative cell. The generative cell divides mitotically and produces two sperm nuclei. When the female part of the flower is matures, the stigma secretes a sugary solution. This promotes the germination of the pollen grain, if viable, compatible pollen comes in contact with this moist stigma. Sexual reproduction in plants is centered in flowers. Co-evolution of flowering plants and their pollinators started about 225 million years ago. ${ }^{6}$ The sexual cycle includes development of the male (pollen) and female (embryo sac) structures of the flower for angiosperms. In this part of the cycle reduction division of the chromosomes occurs to produce the haploid (n) chromosome number i.e., pollen grains and an eight-celled embryo sac contain haploid (1n) male and female gametes, respectively. The germinated pollen grain on the stigma produces a tube (pollen tube) that carries two sperm nuclei (n) down the style into the ovary until it reaches the embryo sac. In the embryo sac, fertilization takes place and hence one sperm fertilizes the egg to form a zygote (2n). The other sperm fuses with the large central cell of the embryo sac to produce a triploid (3n) cell, a process called triple fusion.

\section{Ovule development}

The next step after fertilization is the development of the ovule (containing the zygote and the $3 \mathrm{n}$ central cell) into a seed. ${ }^{7}$ In gymnosperms and angiosperms, seeds develop from ovules. ${ }^{8}$ Ovules consist of a stalk that bears the nucleolus (equivalent to the mega sporangium; diploid maternal tissue). The nucleus is enveloped by one (gymnosperms) or two (angiosperms) covering layers (diploid maternal tissue), called the integuments. An ovule is therefore, in a developmental sense, an unfertilized, immature seed precursor ${ }^{9}$ and, in a morphological and evolutionary sense, a mega sporangium surrounded by integuments. These integuments develop into the test a (seed coat), of which in mature seeds the outer cell layers of the outer integument usually forms a dead covering layer, while inner cell layers may remain alive. ${ }^{10}$ Within the nucleolus, a megaspore develops into a haploid mega gametophyte (female gametophyte). The mega gametophytes of gymnosperms and angiosperms differ considerably. ${ }^{11}$ The mature gymnosperm mega gametophyte is multi cellular, usually several archegonia develop within the mega gametophyte and one egg forms in each archegonium.In most angiosperm species, the mega gametophyte, in its mature state also called the embryo sac, is seven-celled and eight-nucleate, referred to as the Polygonum-type. ${ }^{7}$ The gymnosperms have naked seeds; their seeds are not enclosed by an ovary and are usually found naked on the scales of a cone. In a typical mature gymnosperm seed, the embryo has two covering layers: the haploid maternal mega gametophyte with stored nutrients and the diploid integument tissue that develops into the test a. In contrast to the gymnosperms, the angiosperm ovules and seeds are covered; they are enclosed inside the ovary. The ovary is the base of a modified leaf (carpel) or the fusion between several carpel's in a pistil. A mature ovary contains one or more mature seeds and is called a fruit; a pericarp (fruit coat) develops from the ovary wall and can contain additional flower parts. Both seeds and fruits can be the dispersal units of angiosperms. (Figure 2) A hallmark /characteristics of angiosperm reproduction are double fertilization (Figure 3); that is, in addition to the egg cell fertilization, a second fertilization event occurs in which the central cell nucleus of the mega gametophyte is targeted by a second sperm cell nucleus ${ }^{7}$ This leads to the formation of the endosperm. Since the central cell of most angiosperm species has either one or two nuclei, the resulting fertilized endosperm is either diploid or triploid.

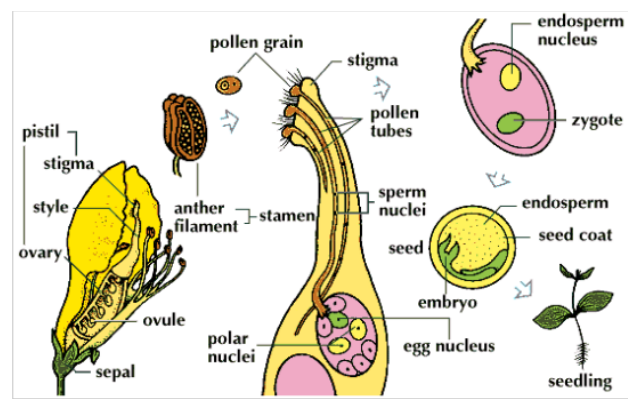

Figure 2 The seed reproduction (pollination and seed embryo, endosperm and seed coat development (http://agritech.tnau.ac.in/seed/seedconcepts. html).
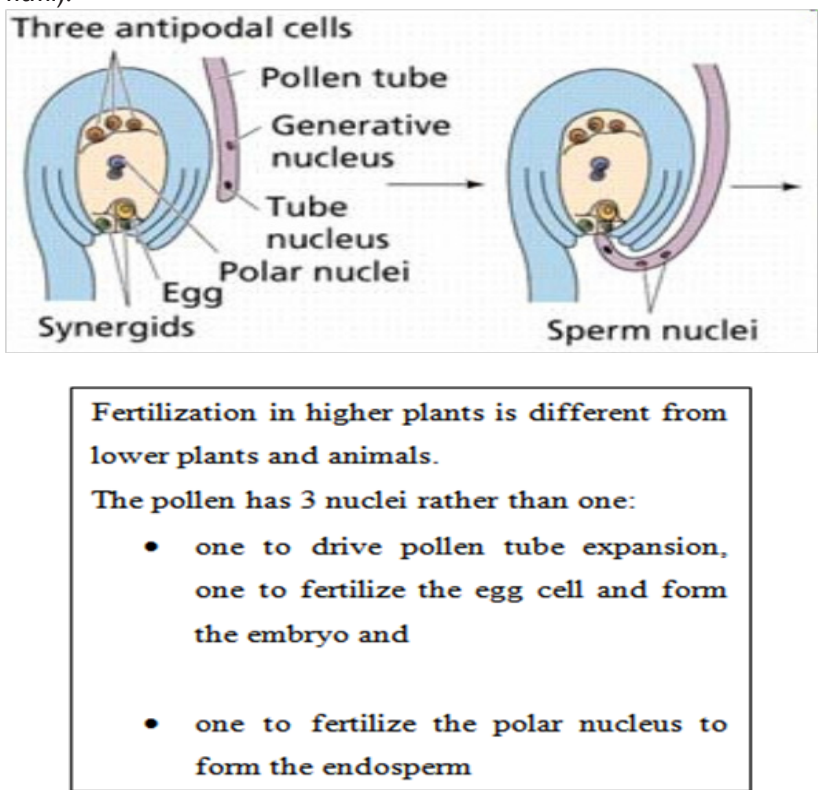

- one to fertilize the polar nucleus to form the endosperm

Figure 3 Embryo development and double fertilization. 


\section{General parameters to characterize seed maturation}

During the 1960s and 1970s, there was a significant effort by seed technologists to clarify the maturation process and to define the primary changes occurring during seed development. The following changes occur during seed development:

Seed moisture content: Ovule moisture content at the time of fertilization is approximately $80 \%$ (fresh weight basis), both for monocots and dicots. That value decreases during maturation although it remains relatively high throughout most of the maturation period because water is the vehicle for transferring nutrients from the parent plant to the developing seeds. ${ }^{12}$ The initial phase of dehydration is slow, and is accelerated from the time the seeds reach maximum dry weight; at that time, seeds possess $35 \%$ to $55 \%$ moisture content for orthodox monocot and dicot seeds, respectively, produced in dry fruits. This decrease in moisture content proceeds until hygroscopic equilibrium is attained. From that point on, moisture content changes are associated with variations in relative humidity. However, seeds produced in fleshy fruits have a lower decrease in moisture content than seeds produced in dry fruits. Developing recalcitrant seeds do not show marked changes in desiccation at the end of maturation, possessing moisture contents usually over $60 \%$ (fresh weight basis).

Seed size: The fertilized ovule is a small structure with respect to final seed size. Plant species with large seeds have an advantage under low light conditions, when their greater protein and lipid reserves, or their more advanced development, can facilitate growth. ${ }^{13}$ However, large seeds usually come at the cost of seed number per flower or fruit. ${ }^{14}$ In addition, large seeds cannot be physically borne on small plants because of the weight of the seed, which may partly explain the association between plant size and seed size (Grubb et al., 2005).

Seed dry weight: After sexual fusion, the developing seeds begin to increase in weight as a result of nutrient accumulation and water uptake. Seed fill is initially slow because cell division and elongation are occurring during this stage. Soon after, dry mass accumulation increases until seeds reach their maximum dry weight. ${ }^{12}$

Germination: Seeds of various cultivated species are able to germinate a few days after ovule fertilization. In this case, germination refers to protrusion of the primary root, not the formation of a normal seedling because histo-differentiation has not been completed and reserve accumulation is still incipient at this phase. Therefore, this germination does not lead to the production of vigorous seedlings. ${ }^{15}$ Theoretically, it is possible to consider that the percentage of germinable seeds increases during maturation, reaching a maximum around the time when seeds attain maximum dry weight. This is only found in species where dormancy does not occur, because the imbalance in the germination promoters/inhibitors induced during the reserve accumulation period may directly affect seed germinability.

Vigor: Seed vigor changes are usually parallel to nutrient reserve transfer from the parent plant. This means that the proportion of vigorous seeds increases during maturation, reaching a maximum near to or at the same time as seed maximum dry weight. ${ }^{12}$

\section{Determination of physiological maturity}

The identification of the time of physiological maturity has been a controversial subject among different authors studying seed maturation. Among the differing physiological maturity concepts, three are dominant: a. Physiological maturity is identified as maximum seed dry matter accumulation

b. Physiological maturity is reached when there is no further significant increase in seed dry weight

c. Physiological maturity occurs when seeds reach maximum dry weight, germination and vigor

According to the prevailing concept, seed development ceases when physiological maturity is achieved, but this idea remains controversial because this expression is frequently used with different meanings. For example, the first concept of physiological maturity was proposed by Shaw and Loomis in 1950 as the stage in which the seed possesses maximum dry weight and yield. Physiological maturity has also been termed "relative maturity" by Aldrich in 1943, morphological maturity" by Anderson in 1955 and "mass maturity" by Ellis and Pieta Filho in 1992 while others prefer to use terms such as "harvest maturity", "agronomic maturity", and "time of harvest" to identify this same stage. Consequently, physiological maturity and harvest time are distinct events. Seed maturation is a process characterized as an organized sequence of several physiological events culminating at physiological maturity, while harvest time is a decision based on technological and economic parameters associated with seed yield/ quality. The determination of physiological maturity usually requires differing measurements of seed dry weight during the seed filling period which is often affected by sampling variation. This makes it difficult to determine the precise time of physiological maturity, i.e., to identify the moment when the transfer of plant reserves to the seed ceases (TeKrony and Egli, 1997). This is perhaps the primary reason why some authors suggest the identification of physiological maturity as the "period in which no more significant increases occur in seed dry weight". Seed dry weight is usually determined at different intervals during maturation. The most frequent method is drying seeds in an oven immediately after harvest followed by weighing the dried seeds for a moisture content determination. Probably the most accurate method of determining physiological maturity is the measurement of $14 \mathrm{C}$ assimilate uptake by the developing seed. This was demonstrated by TeKrony et al. (1979) with soybeans, Lee et al. (1979) with oats and Hunter et al. (1991) with maize seeds. Changes in seed color or other visual changes in seed or fruit structure are also excellent morphological indicators of physiological maturity. For example, physiological maturity was closely associated with yellow color in Dovyalis caffra fruit. ${ }^{16}$ Debate is also found in the research literature regarding the simultaneous expression of maximum germination, vigor and seed dry weight at physiological maturity. Harrington proposed that these three parameters occurred at the same time and could be considered together as markers of physiological maturity. However, although some studies have confirmed this hypothesis, several observations have shown biochemical changes leading to metabolic "adjustments" after seeds reach their maximum dry weight. As a result, the existence of these differing studies about physiological maturity create confusion in the literature that can be attributed primarily to the wide variation in experimental designs and varying concepts of physiological maturity. Finally, the definition of physiological maturity based on seed maximum dry weight should be considered a reference point to characterize the end of seed development and the physiological independence of the seed from the parent plant.

\section{Seed physiological maturity and harvest time}

Physiological maturity identifies the moment seeds possess or 
are close to their maximum physiological potential. As a result, the decision to identify this time as the optimum time for harvesting a seed production area should be logical. ${ }^{15}$ Any harvest delay from the point in which the seed becomes independent of the mother plant may have drastic consequences on seed quality as a result of seed exposure to less favorable environmental conditions for relatively long periods of time resulting in rapid deterioration of the seeds. In the latter collection of fruit of Dovyalis caffra may not be convenient, and also fungal attack may interfere with the germination process, particularly under laboratory conditions. ${ }^{16}$ Generally, visual identification of physiological maturity can help identify the time in which seeds reach their greatest quality or are very close to this time.

\section{Environmental factors affecting seed development}

Components of the environment factors that influence seed performance include soil fertility, water, temperature, light, and seed position on the plant. $^{17}$

Soil fertility: In general, plants that have been fertilized with the three major elements $(\mathrm{N}, \mathrm{P}$, and $\mathrm{K})$ produce larger seeds than those which have not been fertilized. The increase in seed size is due to a enhanced seed development rate during the seed filling period as a consequence of increased nutrient availability. According to Copeland and McDonald ${ }^{17}$ when the effects of individual fertilization elements on seed development are considered, nitrogen has the greatest influence on seed size, seed germination, and vigor.

Water: Water deficits reduce plant metabolism and seed development Research has reported decreases in leaf area, photosynthetic rate, and other effects that promote flower abortion and negatively influence assimilate production and translocation to developing seeds; one of the most important effects is the decrease in carbohydrate supply caused by a reduction in photosynthesis rate. Prolonged droughts and reduced soil water availability cause decreases in seed size, particularly when these effects occur during seed filling. If water deficits occur during flowering, its primary effect is on a reduction in seed number. ${ }^{18}$

Temperature: High temperatures during seed development produce smaller seeds, while low temperatures retard seed growth. Seed germination and vigor are also adversely affected by exposure to low temperatures during development. High temperatures are considered the principal reason for the "forced maturation" of some plants. This phenomenon is also caused by water deficits or desiccant application at inappropriate times during maturation. The occurrence of greenish seeds is undesirable because this abnormality results in decreases in seed germination and vigor. ${ }^{18}$

Light: The seasonal distribution of solar radiation is a fundamental factor in assuring adequate plant development. In general, reduced light to the parent plant results in smaller seeds. ${ }^{18}$

\section{Seed position on the plant}

The position in the inflorescence can affect seed development rate. For example, distal seeds in a wheat spike have slower growth rates and shorter seed filling periods than proximal seeds. Corn seeds at the tip of the ear are smaller than those at the base which has been attributed to inadequate photosynthetic supply. Soybean pods located in lower plant branches are produced before those located in the upper nodes and are affected by different environmental conditions during development and this causes differences in seed performance. Smaller seeds are also produced from smaller fruits or those that mature later in the growing season or are exposed to unfavorable environmental conditions. The usual consequence is decreased seed germination and vigor. $^{12}$

\section{Seed germination/sexual propagation}

Plant propagation is the sexual and asexual multiplication of plants, and has three aspects;

1. Knowledge on the chemical, physical, and environmental manipulations, as well as command of the needed technical skills.

2. Fundamentals of plant biology and physiology.

3. Expertise on specific plant species. ${ }^{16}$

Sexual propagation involves the union of pollen from a male flower part with the egg of a female ovary to produce a seed. Seed can be recalcitrant, inter mediator orthodox seed. The longevity of orthodox seeds is increased over a wide range of environmental conditions by decreasing storage temperature and seed water content without causing significant damage to seed metabolism. Orthodox seeds are, therefore, considered desiccation tolerant. Recalcitrant seeds, however, decrease in viability when their water content is reduced below a relatively high value. They are, therefore, considered desiccation intolerant. The seed is made up of three parts: the outer seed coat, which protects the seed; the endosperm, which is a food reserve; and the embryo, which is the young plant itself. When a seed is mature and put in a favorable environment, it germinates (begins active growth). (Figure 4) Seed germination is a critically important juncture in the plant life cycle and the decision made by an imbibing seed to initiate germination can be considered to be a critical regulatory step in plant development. ${ }^{19}$
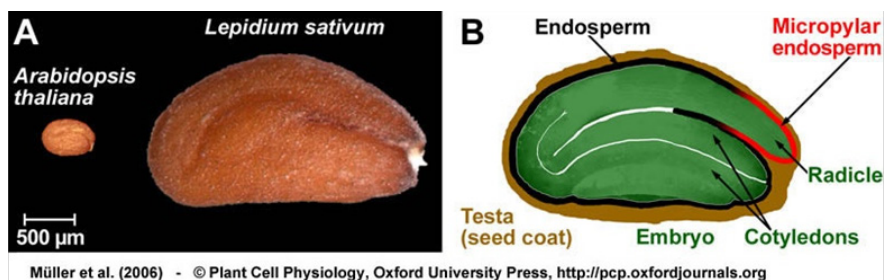

Figure 4 Seed parts.

\section{Stages of seed germination}

\section{$1^{\text {st }}$ Stage}

a. Imbibition - initial absorption of water to hydrate seed

b. Activation of metabolism - increased respiration and protein synthesis

\section{$2^{\text {nd }}$ Stage}

a. Digestion of stored food- for example, starch to sugars in cotyledon or endosperm

b. Translocation to embryo- sugars move to embryo for growth

$3^{\text {rd }}$ Stage: cell division and growth-development of seedling.

Following initial water uptake, this phase of development is characterized by relatively little change in seed water content until it is terminated by the initiation of embryo growth. ${ }^{20}$ During this time, energy metabolism resumes, respiration processes are activated, and the cell cycle may be initiated, while events associated with seed maturation are suppressed..$^{21}$ Sometimes, removal of the developing 
seed from its surrounding fruit tissue is sufficient to permit germination, ${ }^{22}$ but germination of the seed cannot occur even under this situation until near maturation. ${ }^{23}$ The ability of seeds to germinate readily when conditions are suitable for successful growth and the ability to avoid germination at inappropriate times are thus essential to the survival of a species. ${ }^{20}$ The time between seed imbibitions and radical emergence is the period of germination in the strict sense. ${ }^{24}$ According to Hartmann et al., ${ }^{25}$ three conditions are required for germination to be initiated:
1. The seed must be viable,

2. Dormancy of the seed must be overcome,

3. The seed must be subjected to the appropriate environmental conditions: available water, proper temperature regimes, a supply of oxygen, and sometimes light as well as various types of fungi and/or other microorganisms that are needed to decompose seed coat to allow germination. (Figure 5)

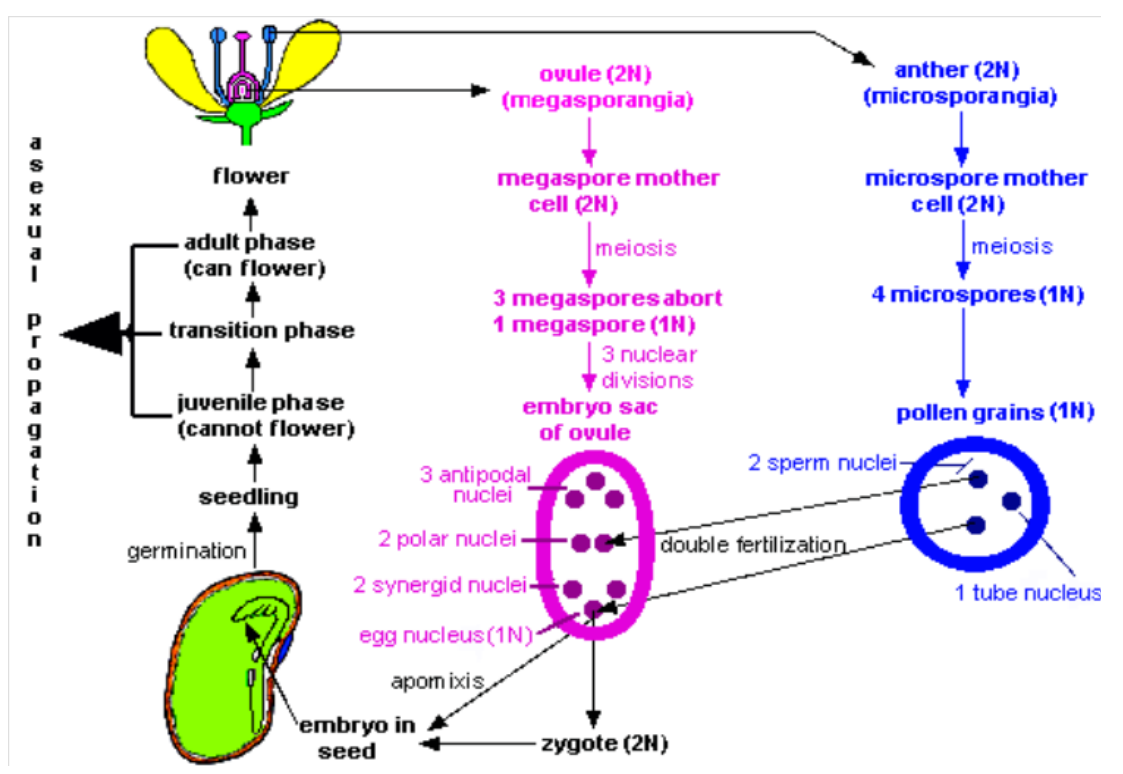

Figure 5 Seed germination process with stages of development.

After the seeds have germinated, they require favorable environment for their establishment. All these factors become available if the seeds have chance to germinate in their original ecology or if the original ecology is not seriously disturbed. ${ }^{26}$

\section{Factors affecting seed germination}

Germination potential of seeds of many plants can be influenced by various environmental and the seed internal factors. Without understanding of such factors and appropriate knowledge of plant propagation techniques and their seed biology of indigenous trees, production of seedlings from seeds would be difficult. ${ }^{16,26}$ This is due to the existence of unique survival and developmental strategy of each indigenous tree species through long time of evolutionary processes. One of the major strategies in seed physiology is: some seeds of indigenous tree species undergo the period of dormancy to pass unfavorable environmental or internal situations. The germination of seeds in a particular situation and season is determined by the interaction between the dormancy releasing factors, which influence on the termination of dormancy or initiation of germination and seedling growth in many plant species like Phyto-hormones, light, temperature, water, nutrients, moisture or mechanical cues. ${ }^{21}$

\section{Seed maturity and dormancy}

Propagations of many indigenous tree species from seeds had been difficult due to lack of precise knowledge on their seed biology and germination physiology. ${ }^{26}$ Many native plant species developed survival strategies through evolutionary processes for millions of years. So they must simultaneously sense a number of environmental conditions and fix time of seed maturation and germination and seedling emergence to particular periods of the year according to their habitat locations for successful establishment and survival. Seed set and releases of seeds into the soil occur at the pick of the dry season and emergence of seedlings under this condition could jeopardize survival. Hence a structural or physiological adaptive mechanism called dormancy prevents seed germination. ${ }^{26} \mathrm{~A}$ seed becomes dormant when growth potential of the embryo falls below the restraining force of its covering structure. Seed dormancy is defined as the state in which otherwise mature and viable seeds will not germinate even when exposed to favorable growth conditions..$^{25}$ Dormancy is a resting stage. Seeds will only germinate when the conditions are suitable. Some causes of seed dormancy are:
a) Hard seed coat
b) Embryo dormancy
c) Immature embryo- the embryo is not fully developed when the seed is dispersed
d) Chemical inhibitor

\section{Types of dormancy}

1. Quiescent seed dormancy -even a non-dormant or quiescent seed has a unique ability to revert to a dormant state under stressful conditions. ${ }^{25}$ Dormancy is desired in the wild, where 
plants depend entirely on nature for survival. ${ }^{26}$ Seeds dormancy has intrigued biologists and frustrated horticulturists for many years because matured seeds fail to germinate if planted immediately without a rest period. ${ }^{25}$

2. Structural dormancy is imposed via seed coat, which prohibits the entry of water, air, outward diffusion of possible endogenous germination inhibitors, as well as through mechanical restriction of embryo growth. ${ }^{25}$ Species with hard, impervious seed coverings occur in trees such as Podocarpus falcatus, Olea europaea and various Acacia species. ${ }^{26}$ To help such seeds to germinate, mechanical methods were employed to loosen the seed covering by cracking the seed coat. Similarly seeds of Prunus africana were found to germinate by seed coat scarification. ${ }^{27}$

3. Physiological dormancy (embryo dormancy) occurs when the embryo requires a special treatment to induce it to start active growth. A cold temperature application of about 1 to $7^{\circ} \mathrm{C}$ is commonly required to break the dormancy. ${ }^{25}$ In some plant species, embryo dormancy can be broken by a certain quality of light. For example, exposure of lettuce seeds to red light (about $660 \mathrm{~nm})$ induces germination, but far red light $(730 \mathrm{~nm})$ inhibits it. ${ }^{28}$ It was indicated long years ago that if lettuce seeds received red light after exposure to far red light, germination occurred and the germination of seeds of this species can occur only as long as the last treatment before sowing was red light. ${ }^{25}$

\section{Way of dormancy breakage}

Seeds germinate only after the dormancy is overcome or broken either through;

1. Natural means such as animal gut activities (Manzano et al., 2005), wild fire, rainfall ${ }^{25}$ or through

2. Artificial means such as scarification, seed coat cracking, removing chemical inhibitors through leaching by water etc. ${ }^{29}$

For example, Acacia seeds dormancy removed by scarifying seed coat, Podocarpus falcatus dormancy removed by cracking away the latter using a piece of clean basalt rock (ca 200-300). ${ }^{16}$

1. Scarification: Scarification is when the seed coat is rubbed with something such as sandpaper. This makes the seed coat thinner so water can enter more easily. This method is best for smaller seeds that are hard to cut for example kaka beak. To do this easily you can shake the seeds forcefully in a container lined with sandpaper

2. Chipping seeds: Chipping is cutting a small piece out of seed coat with a sharp knife. Water can then enter the test a through the cut. This is useful on large seeds for example, sweet pea

3. Soaking seeds: Soaking seeds in water overnight will soften the test a. This can be useful for seeds such as wattle, sweet pea and kowhai. Commercial growers use diluted acids on some seeds

4. Immature embryo: the embryo is not fully developed when the seed is dispersed. Therefore, Store seeds before planting. Waiting for a period of time will allow the embryo to mature

5. Chemical inhibitors: Some seeds contain chemicals that prevent germination. This is common in fleshy fruit but it depends on the seed type as to what will get rid of the inhibitor

The ability of seeds to germinate readily when conditions are suitable for successful growth and the ability to avoid germination at inappropriate times, through the maintenance of dormancy, can also be controlled by endogenous chemicals. ${ }^{19}$ Seed of some fleshy fruits, such as strawberry and tomato, will not germinate in the fruit because of the presence of chemical germination inhibitors. ${ }^{22}$ Some desert plant seeds germinate only after a heavy rain, the seedlings assured adequate moisture for survival and development until their roots are developed enough to absorb moisture. ${ }^{30}$ A number of chemicals in plants inhibit germination of seeds while they are still embedded in the pulp of the fruit. For example, in tomato and strawberry. ${ }^{22}$ Seed maturity can also affect seed germination and the emergence of seedlings in many cases. In some species, such as Pinus and Rananculus, the fruits are shed before the embryo fully matures. Such physiologically immature seeds must undergo certain enzymatic and biochemical changes to attain maturity. ${ }^{25}$ These changes are collectively called after ripening. Immature embryos cannot germinate. But such seeds can be matured artificially by storing fruits or cones for a certain period of time to allow embryos to mature completely and to germinate. ${ }^{31}$ Investigation of the germination physiology of seeds of several indigenous tree species of Ethiopia have shown that a certain level of maturity must be reached for the successful germination of the seeds to produce the required amount of seedlings for mass propagation of forest trees. ${ }^{26}$ For example, in $P$. falcatus, fruit collection should be commenced when at least $60-70 \%$ of them become yellow to get high quality viable seeds. Seed germination studies of Bixaorellana by Hill et al., ${ }^{32}$ indicated that the more matured seed germinated faster, had a higher total germination, and produced more vigorous seedlings. For a given species, it is often the case that either the presence of an impermeable, leathery or hard seed coat or chemical inhibitors within the embryo or within the stored food of the seed or the embryo immaturity prevent seed germination. However, it can sometimes happen that all the three factors can combine and prevent seed germination..$^{25}$ Therefore, the problem associated with seed germination that prevent successful seedling production, depend much on the understanding of the biology of seed dormancy and the seed maturity condition of the species of interest.

Storage time and temperature: Seed germination can be determined by many factors including seed storage time and temperature. Legesse Negash (2003) indicated that germination of P. falcatus had shown to be declined with increased storage time. Temperature is the most important environmental factor that regulates the aging of seeds, partly due to the increased deterioration following long-term storage under high temperature or under poor storage conditions (Legesse Negash, 2003). Storage time and temperature affects both germination percentage and rate of germination. For example, Legesse Negash (2003) has indicated that germination rate of $P$. falcatus was better when stored at lower temperature but decreased with increased storage temperature. Germination percentage, unlike germination rate, may remain relatively constant, at least over the middle part of the temperature range if sufficient time is allowed for germination to occur. ${ }^{26}$ With proper handling and storage, seed longevity may be maintained for significant periods. However, the processing, the rate of physiological change, storage and germination conditions for many indigenous tree seeds are poorly understood and hence they may look healthy but fail to germinate when planted due to seed short viability conditions as well as lack of the knowledge of their reproductive biology. ${ }^{29}$ Viability at the end of storage depends on:

a. The initial viability at harvest, as determined by factors of production and methods of handling; and

b. The rate at which deterioration takes place. Basic features of storage that increases the viability of seeds ${ }^{26}$ include 
c. Protection from water,

d. Avoidance of mixture with other seed,

e. Protection from rodents, insects, fungi, and others. Retention of viability also varies with the climatic factors of the area in which storage occurs.

Viability is a measure of the propagation of seeds in a lot that are capable of germinating while longevity is a measure of how long seeds remain viable. ${ }^{28}$ The relative storability index depends on the kind of seeds (recalcitrant or orthodox), condition of seeds at the beginning of storage and environmental conditions of storage, primarily temperature and humidity and it indicates the storage time where $50 \%$ or more of seeds can be expected to germinate. ${ }^{25}$ Species with recalcitrant or short-lived seeds normally retain viability for little as few as days, months, or at most a year following harvest. ${ }^{33}$ But if properly stored recalcitrant seeds will retain viability for longer periods up to four to five years. ${ }^{34}$ Storage conditions that reduce seed deterioration are those that slow respiration and other metabolic processes without injuring the embryo. ${ }^{33}$ Poorest conditions are found in warm, humid climates; best storage conditions occur in dry, low storage temperature and modification of the storage atmosphere. ${ }^{34}$ Of these, the moisturetemperature relationships have the most practical significance. ${ }^{33}$ J.F. Harrington (1963; cited in Hartmann et al., ${ }^{25}$ indicated that seeds loose half of their storage life for every $1 \%$ increase in seed moisture between 5 and $14 \%$ and for every $5^{\circ} \mathrm{C}$ increase in storage temperature between 0 and $50^{\circ} \mathrm{C}$. Recalcitrant seeds owe their short life primarily to their sensitivity to low moisture and they can lose their viability when the seed moisture content dropped below $30 \% .^{27}$

\section{Seed treatments related to fire}

Seeds of many fire-adapted plants are very difficult to germinate, and some species have been impossible to propagate by seeds. ${ }^{35}$ Numerous species, which inhabit fire dependent ecosystem, have evolved reproductive strategies to adapt to factors associated with fire $^{36}$ and many of them have evolved barriers to seed germination that are overcome only by fire-related cues. ${ }^{37}$ Recurring fires are an integral part of many ecosystems, and when such areas are protected from forest fire; their local ecology becomes severely disturbed. Plant species use this strategy is described as "Hard seeded" with a prominent waxy cuticle that enforces dormancy by forming a water-impermeable barrier. ${ }^{38}$ The positive effect of smoke on seed germination is not limited to species native to fire-prone habitats. Smoke has been used to break dormancy and improve germination of seeds of common vegetables without obvious need of fire for their germination such as lettuce ${ }^{39}$ and celery. ${ }^{40}$ Seeds of many recalcitrant species were found to break dormancy upon contact with smoke, or even with wood ash. ${ }^{37}$

\section{Gibberellic acid (GA3)}

Gibberellins are a group of plant growth regulators which play an important role in the regulation of seed germination and breaking dormancy. According to Taiz \& Zeiger, ${ }^{41}$ seed germination may require gibberellins for one of several possible steps: the activation of vegetative growth of the embryo, the weakening of a growth constraining endosperm layer surrounding the embryo, and the mobilization of stored food reserves of the endosperm. Seed germination can be stimulated by applying artificially produced Phyto-hormones or by natural means. In a natural means of breaking dormancy, the gibberellins synthesizing mechanism is activated and the actual synthesis of gibberellins takes place when the seeds are transferred to a suitably higher temperature. ${ }^{42}$ Consequently, accumulation of GA results in germination of seeds. Gibberellins promote growth by increasing plasticity of the cell wall followed by the hydrolysis of starch to sugar which reduces the potential in the cell, resulting in the entry of water into the cell causing elongation, hence, causing germination of seeds. Releasing from dormancy can be affected by a variety of environmental and chemical stimuli. It is mediated through a common signal transduction chain that coordinates diverse cellular responses but that may differ between the seeds of different species and dormancy types. Gibberellic acid is known to break dormancy of several types of plant seeds: these are

a. Light promoted seeds, such as grand rapids lettuce seed (Lactuca sativa L. var. Grand Rapids)

b. Light inhibited seeds, such as the seed of the honey bee plant (Phacelia tanacetifolia Benth)

c. Seeds requiring stratification (storage at low temperatures in a moist condition), such as the hazel nut (Corylusavellana L.)

d. Seeds requiring after ripening (storage at room temperature in dry condition), such as the wild oat (Avenafatua L.) as reported by Chen \& Change. ${ }^{42}$

\section{Potassium nitrate (KNO3)}

Nitrogenous compounds, especially nitrates promote the seed germination of a wide range of plant species. The effect of such a nitrate compounds on promotion of seed germination is best realized in combination with other factors such as temperature manipulations or light. ${ }^{43}$ In assessment of the interaction of nitrate with growth regulators, the phenomena initiated by many environmental factors, that interacts through altering the availability of endogenous hormones ${ }^{42}$ Plant hormones and environmental factors can often bring out identical responses in seeds, but a causal relationship between the two remains a matter of much controversy. However, potassium nitrate (KNO3) was most widely used chemical for promoting germination and for breaking seed dormancy. For this purpose solutions of 0.1 to $0.2 \% \mathrm{KNO} 3$ were common in usual germination testing and are recommended by the Association of Official Seed Analysts (AOSA) and the International Seed Testing Association (ISTA) for germination tests of many species. ${ }^{44}$ Both higher and lower concentration of KNO3 has effect on germination of seeds of many plants. Yucel \& Yilmaz, ${ }^{44}$ reported that lower concentration of KNO3 $(<1 \%)$ inhibit germination of Salvia cyanescens seeds. The optimum germination rate was better in $1 \%$ concentration series and when $\mathrm{KNO} 3$ exceeds $2 \%$ in concentration, it becomes a germination inhibitor. ${ }^{45-52}$

\section{Conclusion and recommendations}

The evolution of the seed represents a remarkable transition for photosynthetic organisms. Furthermore, seeds remain in a state of dormancy induced by desiccation and the hormone abscisic acid until conditions for growth become favorable. Whether blown by the wind, floating on water, or carried away by animals, seeds are scattered in an expanding geographic range, thus avoiding competition with the parent plant. Seed evolution eliminates requirement for water during sexual reproduction and allows fertilization event to occur over long distances. In conclusion seeds of different plants need different pretreatment to get vigor seedling and even for production. Therefore, real attention should be given for the plant propagation, particularly 
for indigenous tree species and seedling multiplication should be considered as our culture to make suitable environment.

\section{Acknowledgments}

I would like to acknowledge all the previous investigators who produced valuable research articles and availed for this review paper.

\section{Conflict of interest}

The author declares there is no conflict of interest.

\section{References}

1. Bhattacharya D, Medlin L. Algal Phylogeny and the Origin of Land Plants. Plant Physiol. 1998;116(1):9-15.

2. Willis KJ, McElwain JC. The Evolution of Plants. Chicago: Oxford University Press; 2002: 378p.

3. Cantino PD, Doyle JA, Graham SW, et al. Towards a phylogenetic nomenclature of Tracheophyta. Taxon. 2007;56(3):822-846.

4. Gerhard Leubner-Metzger, Ada Linkies, Kai Graeber, et al. The evolution of seeds. New Phytologist. 2010;186:817-831.

5. Baskin JM, Baskin CC. Physiology of dormancy and germination in relation to seed bank ecology. In: Leck MA, Parker VT, Simpson, RL, editors. New York: Ecology of Seed BanksAcademic press;1989:53-69.

6. Traverse A. Plant evolution dances to different beat. Historical Biology. 1988a;1(4):277-301.

7. Price P. Insect Ecology. USA: John Wiley and Sons; 1975.

8. Friedman WE, Ryderson KC. Reconstructing the ancestral female gametophyte of angiosperms: insights from Amborella and other ancient lines of flowering plants. Am J Bot. 2009;96(1):129-143.

9. Frohlich MW, Chase MW. After a dozen years of progress the origin of angiosperms is still a great mystery. Nature. 2007;450(7173):11841189.

10. Gasser CS, Broadhvest J, Hauser BA. Genetic analysis of ovule development. Annual Review of Plant Physiology and Plant Molecular Biology. 1998;49:1-24.

11. Haughna G, Chaudhuryb A. Genetic analysis of seed coat development in Arabidopsis. Trends Plant Sci. 2005;10(10):472-477.

12. Baroux C, Spillane C, Grossniklaus U. Evolutionary origins of the endosperm in flowering plants. Genome Biology. 2002;3(9):1026.

13. McDonald MB. Seed germination and seedling establishment. In Boote KJ, Bennett JM, editors. Physiology and Determination of Crop Yield. Crop Sci. Soc. Amer., Madison, WI; 1994.

14. Bruun HH, Ten Brink DJ. Recruitment advantage of large seeds is Greater in shaded habitats. Ecoscience. 2008;15(4):498-507.

15. Leishman MR. Does the seed size/number trade-off model determine plant community structure? An assessment of the model mechanisms and their generality. Oikos. 2001;93(2):294-302.

16. McDonald MB. Seed priming. In: Black M, Bewley JD, editors. Seed Technology and Its Biological Basis. New York: Plenum Press; 2000.

17. Legesse Negash. A selection of Ethiopia's Indigenous Trees: Biology, Uses and Propagation Techniques. Addis Ababa University Press, Addis Ababa; 2010: 386p.

18. Copeland LO, McDonald MB. Principles of Seed Science and Technology. ${ }^{\text {th }}$ edn, Kluwer Academic Publishers. Boston; 2001: 467p.

19. Yamada T, Imaichi R, Kato M. Developmental morphology of ovules and seeds of Nymphaeales. American Journal of Botany.

\section{1;88(6):963-974.}

20. Johnson R. Characterization of germination related genes in Avenafatua seeds. In: Black M, Bradford KJ, Vazquez-Ramos J, editors. Seed Biology Advances and Applications, Proceedings of the sixth International Workshop on Seeds, Mérida, México, 1999. CABI Publishing; 2000:1-17.

21. Bray CM. Biochemical Processes during the Osmopriming of Seeds. In: Kigel J, Galili G, editors. Seed Development and Germination. Marcel Dekker, New York; 1995;67-789.

22. Hilhorst HWM, Groot SPC, Bino RJ (1998). The tomato seed as a model system to study seed development and germination. Acta Botanical Neerlandica. 1998;47(2):169-183.

23. Berry T, Bewley JD. A role for the surrounding fruit tissues in preventing the germination of tomato (Lycopersico esculentum) seeds: a consideration of the osmotic environment and abscisic acid. Plant Physiol. 1992;100(2):951-957.

24. Bewley JD, Downie B. Is failure of seeds to germinate during development a dormancy-related phenomenon? In: Lang GA, editor. Plant Dormancy Physiology, Biochemistry and Molecular Biology. CAB International, Wallingford; 1996:17-27.

25. Bradford KJ, Chen F, Cooley MB. Gene Expression Prior to Radicle Emergence in Imbibed Tomato Seeds. In: Black M, Bradford KJ, Vazquez-Ramos J, editors. Seed Biology advances and Applications. Proceedings of the sixth International Workshop on Seeds, Mérida, México, 1999. CABI Publishing; 2000;18-30.

26. Hartmann HT, Kester DE, Davies FT, et al. Plant Propagation. 1997.

27. Legesse Negash. Indigenous Trees of Ethiopia: Biology, Uses and Propagation Techniques. SLU Reprocentralen, Umeå Sweden. 1995; $285 \mathrm{p}$.

28. Legesse Negash. Rapid seed-based propagation method for the threatened African Cherry (Prunus africana). New Forests 2004;27(3):215-227.

29. Acquaah G. Horticulture Principles and Practices, Second edition. Prentice-Hall ofIndia Pvt Ltd. 2002.

30. Legesse Negash. Review of research advances in some selected African trees with special reference to Ethiopia. Ethiop J Biol Sci. 2002a; $1: 81-126$.

31. McCarty DR, Carson CB. The Molecular genetics of seed maturation in maize. Physiologia Plantarum. 1991;81(2):267-272.

32. Yogeesha HS, Shivananda TN, Bhanuprakash K. Effect of seed maturity, seed moisture and various pre-treatments on seed germination of annatto (BixaorellanaL.). Seed sci. Tech. 2006;33(1):97-104.

33. Hill NS, Bouton JH, Hiatt EE, et al. Seed Maturity, Germination, and Endophyte Relationships in Tall Fescue. Crop Sci. 2005;45(3):859-863.

34. Anguelova Merhar VS, Calistru C, Berjak P. A study of some Biochemical and Histopathological Responses of Wet-stored Recalcitrant Seeds of Avicennia marina Infected by Fusarium moniliforme. Ann Bot. 2003;92(3):401-408.

35. Bewley JD, Black M. Seeds: Physiology of Development and Germination.New York: Plenum Press; 1994.

36. Keeley JE. Seed germination and life history syndromes in the California Chaparral. Botanical review. 1991;57(2):81-116.

37. Van Staden J, Brown NAC, Jager AK, et al. Smoke as a germination cue. Plant Species Biology. 2000;15(2):167-178.

38. Keeley JE, Fotheringham CJ. Smoke-induced seed germination in California Chaparral. Ecology. 1988;79:2320-2336.

39. Keeley JE, McGinnis TW, Bollens KA. Seed Germination of Sierra 
Nevada Post fire Chaparral Species. Madroño. 2005;52(3):175-181.

40. Drewes FE, Smith MT, van Staden J. The effect of a plant-derived smoke extract on the germination of light-sensitive lettuce seed. Plant Growth Regulation. 1995;16(2):205-209.

41. Brown NAC, van Staden J. Plant-derived smoke: an effective seed pre-soaking treatment for wildflower species and with potential for horticultural and vegetable crops. Seed Sci Tech. 1999;26:669-673.

42. Taiz L. Zeiger E. Plant Physiology. $3^{\text {rd }}$ edn, Sinauer Associates, Sunderland; 2000: 690 p.

43. Cheng SSC, Change JLL. Does gibberellic acid stimulate seed germination via amylase synthesis? Plant Physol. 1972;49(3):441-442.

44. Saini HS, Bassi PK, Spencer MS. Seed germination in Chenopodium album L. relationship between nitrate and the effects of plant hormones. Plant Physol. 1984;77(4):940-943.

45. Basra AS. Seed Quality Basic Mechanism and Agricultural Implications. Food Products Press; 1994: 386 p.

46. Yucel E, Yilmaz G. Effects of different alkaline metal salts $(\mathrm{NaCl}$, $\mathrm{KNO}_{3}$ ), Acid concentrations $\left(\mathrm{H}_{2} \mathrm{SO}_{4}\right)$ and growth regulator $\left(\mathrm{GA}_{3}\right)$ on the germination of Salvia cyanescens Boiss. \& Bal. Seeds. G.U. J. Sci.
2009:123-127.

47. Bateman RM, Crane PR, DiMichele WA, et al. Early evolution of land plants: phylogeny, physiology and ecology of the primary terrestrial radiation. A Rev Ecol Syst. 1998;29:263-292.

48. Bell DT, Rokich DP, McChesney CJ, et al. Effects of temperature, light and gibberellic acid on the germination of seeds of 43 species native to Western Australia. Journal of Vegetation Science. 1995;6(6):797-806.

49. Fenner M. Ecology of seed banks. In: Kigel J, Galili G, editors. Seed Development and Germination. Marcel Dekker, Inc., New York. 1995.

50. Principles and Practices. $6^{\text {th }}$ edn, Prentice-Hall of India Private Limited, New Delhi; 2002.

51. Legesse Negash. Investigation on the germination behaviour of wild olive seeds and nursery establishment of the germinants. SINET Ethiop J Sci. 1993;16:71-81.

52. Michael G Sampson. Plant Systematic: Evolution and Diversity of Woody and seed plants. UK: Elsevier Academic Press; 2006: 603 p.

53. Traverse A. Plant evolution dances to different beat. Historical Biology. 1988a;1(4):277-301. 